\title{
Waist circumference measures: cutoff analyses to detect obesity and cardiometabolic risk factors in a Southeast Brazilian middle-aged men population - a cross-sectional study
}

\author{
Alessandro de Oliveira ${ }^{1,2^{*}}$, Paula G Cocate ${ }^{1}$, Helen Hermana M Hermsdorff ${ }^{1}$, Josefina Bressan ${ }^{1}$, \\ Mateus Freitas de Silva ${ }^{3}$, Joel Alves Rodrigues ${ }^{3}$ and Antônio José Natali ${ }^{3}$
}

\begin{abstract}
Background: Low-cost practical and reliable tools to evaluated obesity-related cardiometabolic diseases are of clinical practice and public heath relevance worldwide. The aims of this cross-sectional study were to determine the anatomical point of waist circumference that best identify overweight, obesity and central obesity in Southeast Brazilian middle-aged men and to test the relationships of its cutoff points with metabolic syndrome (MetS), insulin resistance (IR) and cardiometabolic risk factors.

Methods: Three hundred men [age: 51 (47-54)] underwent anthropometric, body composition, clinical, sociodemographic and blood plasma biochemical evaluations.

Results: The umbilical line circumference $\left(W C_{U L}\right)$ was the best predictor for overweight (total body fat $\geq 20 \%$; cutoff point: $88.8 \mathrm{~cm}$ ), obesity (total body fat $\geq 25 \%$; cutoff point: $93.4 \mathrm{~cm}$ ) and central obesity (abdominal area fat $\geq 34.6 \%$; cutoff point: $95.6 \mathrm{~cm}$ ) as measured by dual beam X-ray absorptiometry. Subjects with $W C_{U L} \geq 88.8 \mathrm{~cm}$ or $\geq 93.4 \mathrm{~cm}$ showed significantly higher values for MetS, IR and cardiometabolic risk factors (i.e. glucose and lipid profiles, blood pressure). The occurrence of $W C_{U L} \geq 88.8 \mathrm{~cm}$ was positively associated $(p<0.01)$ with the prevalence of MetS and cardiometabolic risk factors and increased the central obesity prevalence by $19.3 \%$ while that of $W C_{U L} \geq 93.4 \mathrm{~cm}$ was associated with the prevalence of MetS, IR and cardiometabolic risk factors.
\end{abstract}

Conclusions: WCUL measure seems to be the best predictor for overweight, obesity and central obesity in urban residents Southeast Brazilian middle-aged men; and the $W C_{U L}$ cutoff point $(88.8 \mathrm{~cm})$ is significantly associated with MetS, IR and cardiometabolic risk factors in the studied population.

Keywords: Obesity, Waist circumference, Non-communicable disease, Metabolic syndrome

\section{Introduction}

Obesity is a major public health problem worldwide. The accumulation of fat in the body, especially in the central region, is positively associated with the development of chronic non-communicable diseases (NCDs) [1-4].

Metabolic syndrome (MetS) is characterized by an aggregation of relevant cardiometabolic risk factors, such

\footnotetext{
* Correspondence: alessandro@ufsj.edu.br

1 Department of Nutrition and Health, Universidade Federal de Viçosa, Av. PH Rolfs, s/n, Viçosa, Minas Gerais 36570-000, Brazil

${ }^{2}$ Department of Physical Education Science and Health, Universidade Federal de São João del-Rei, São João del-Rei, Minas Gerais, Brazil

Full list of author information is available at the end of the article
}

as abdominal obesity, dyslipidaemia, high blood pressure and high fasting blood glucose [3]. Metabolic syndrome is more prevalent in Brazilian subjects over 40 years of age, with prevalence ranging from $23 \%$ up to $39.2 \%$, depending on the geographic region, gender, age and criteria of diagnosis [5,6]. Insulin resistance (IR) is a common pathologic state in which target cells fail to respond to ordinary levels of circulating insulin and, like MetS, it is an important metabolic risk factor for diabetes and cardiovascular diseases [7]. However, no data on IR prevalence in the Brazilian population is available and IR is 
not internationally agreed upon as a criterion in the diagnosis of MetS, making it a matter of debate [8].

The early diagnosìs of MetS, IR and related cardiometabolic risk factors in populations is of clinical importance and economical relevance. Nevertheless, the diagnosis of both MetS and IR in large-scale populations is limited by the high cost of biochemical analyses and the exposure of the volunteer to invasive procedures (i.e. discomfort to locate the anatomical points for anthropometric measurements; and blood collection). Thus, lowcost practical and reliable measurements such as central circumferences are of clinical and public health relevance worldwide. The waist circumference (WC) measure has been shown as a good predictor for central obesity $[2,9]$ and hence cardiometabolic risk factors [10], IR [11] and MetS prevalence [12]. However, there are limitations in the use of such measure (i.e. midpoint between the superior border of the iliac crest and inferior margin of the rib), mainly in overweight and obese subjects, as some anatomical points are not precisely identified on them $[13,14]$. Moreover, the lack of a standardized method for WC measures by the organizations responsible for NCDs standards hinders comparison between different geographic regions $[15,16]$.

Along with early diagnosis of NCDs by using simple measurements, it is important to set cutoff points for specific populations as WC differs among different ethnic groups due to distinct prevalence of cardiometabolic risks [17]. Previous studies have suggested different values of WC cutoff points for the diagnosis of obesity and chronic diseases as compared to those generally used (i.e. Alberti et al. [3]: $90 \mathrm{~cm}$ for South American population) $[18,19]$. For example, $94 \mathrm{~cm}$ for 21-95 old Latin Americans (Mexico, El Salvador, Venezuela, Colombia and Paraguay) [18] men as well as $90.2 \mathrm{~cm} \mathrm{[19]} \mathrm{and} 88 \mathrm{~cm}$ [20] for urban residents in the northeast region of the Brazil aged 20-59 years were suggested. However, studies suggesting WC cutoff points for the early detection of NCDs, specifically in Brazilian middle-aged men (40-59 years old), are not found.

Therefore, this study was carried out to: (a) determine one anatomical point of WC that best identify overweight, obesity and central obesity in urban resident Southeastern Brazilian middle-aged men; and (b) test the relationships of its cutoff points with MetS and IR prevalence and, cardiometabolic risk factors in this population.

\section{Methods}

\section{Study population}

This cross-sectional study was carried out between March and December 2011. By convenience, we studied the population of middle-aged men who were staff members of the Federal University of Viçosa, located in the Brazilian southeastern city of Viçosa, Minas Gerais state. This population consisted of $1,774(\mathrm{~N})$ men aged between 40-59 years. The sample size was calculated using the confidence level of $95 \%$ and the prevalence for obesity in Brazilian men (i.e. 17.5\%), as detected by the Brazilian Health Minister [4], and 4\% of sampling error, which resulted in 291 (n) participants as a minimum sample size required. The Epi Info software, version 6.04, for cross-sectional studies [21] was used to estimate sample size.

To select the subjects of this study all 1,774 staff members were listed and numbered alphabetically and those numbered multiple of $6(\mathrm{~N} / \mathrm{n}: 1,774 / 291)$ were chosen. In the event of meeting the exclusion criteria the subject was replaced by his predecessor in the list. Eight hundred fifty-six subjects were interviewed and 300 of them were eligible to take part in the present study.

This study excluded subjects who self-declared: body weight alterations of $\geq 3 \mathrm{~kg}$, altered levels of physical activity and eating habits in the three months preceding the study; thyroid diseases, heart failure, cerebrovascular diseases, infectious and/or inflammatory diseases, diseases of the gastrointestinal tract, liver and chronic kidney and/or history of kidney stones, cancer in the previous ten years, eating disorders (anorexia and bulimia) and food allergies. Subjects using diuretics or drugs that could alter food intake and/or metabolism of nutrients were also excluded. Pacemaker and/or prosthetic users were excluded as it could affect the DXA result analyses. Elite athletes were excluded as they could exhibit an inflammatory condition due to exercise training stress.

This study is in accordance with the resolution 196/96 from the Brazilian Ministry of Health regarding research involving human subjects and was approved by the Ethics Committee on Human Research of the Federal University of Viçosa (Of. Ref. n 069/2010/CEPH). Only participants who signed the consent form in accordance with the Declaration of Helsinki were selected.

\section{Anthropometry and body composition measurements}

Anthropometry and body composition measurements were carried out after a 12-hour fast and the subjects were instructed to perform no physical activities of moderate and high intensity and no caffeine and alcohol ingestion in the 48 hours prior to the test.

Body weight and height were determined following the protocol described by Gordon et al. [22], using a digital scale with stadiometer (2096PP, Toledo, São Bernardo do Campo, SP, Brazil). Body mass index (BMI) was calculated using the equation proposed by Quetelet and the subjects were categorized as: eutrophic (18.5 to $24.9 \mathrm{~kg} / \mathrm{m}^{2}$ ), overweight ( 25.0 to $29.9 \mathrm{~kg} / \mathrm{m}^{2}$ ) or obese $\left(\geq 30 \mathrm{~kg} / \mathrm{m}^{2}\right)$, according to the criteria set by the World Health Organization [23]. 
Waist circumferences were measured on three anatomical points: (a) narrowest waist $\left(\mathrm{WC}_{\mathrm{NR}}\right)$ [24] (i.e. nearly $1 \mathrm{~cm}$ below the last rib); (b) midpoint between the superior border of the iliac crest and inferior margin of the rib $\left(\mathrm{WC}_{\mathrm{MD}}\right)[2,3]$ (i.e. nearly $3 \mathrm{~cm}$ above the umbilical line); and (c) at the umbilical line ( $\mathrm{WC}_{\mathrm{UL}}$ ) [25]. Waist circumferences were measured in triplicate using a flexible, no stretching tape (TR4010, Sanny, São Bernardo do Campo, SP, Brazil) and the average value for each anatomical point was considered for data analyses.

Total body scan was performed by dual beam X-ray absorptiometry (DXA) (LUNAR, GE, Encore software version 13:31, Madison, WI, USA) to determine the percentages of total body fat $(\% \mathrm{BF})$ and abdominal area fat (\%AAF). Abdominal area fat is the body fat detected in the area between the superior border of the iliac crest and the inferior border of the last rib. Overweight and obesity cutoff values were set at $20 \%$ and $25 \%$ of $\%$ BF $[26,27]$, respectively. Since there is no cutoff points for $\% A A F$ reported, the percentage found in the 75 th percentile of \%AAF in the present sample was used for central obesity.

\section{Blood pressure, blood glucose, insulin and serum lipid profile measurements}

Systolic (SBP) and diastolic blood (DBP) pressure were measured using an automatic inflation blood pressure monitor (BP3AA1-1, G-Tech, OnboElectronicCo, Schenzen, China), registered at ANVISA (No. 80275310004), following the VI Brazilian Guidelines on Hypertension [28].

Blood samples were collected from the antecubital vein and the serum was separated by centrifugation at $2.225 \mathrm{~g}$ for $15 \mathrm{~min}$ at room temperature (Sigma 2-3, Sigma Laborzentrifuzen, OsterodeamHarz, Germany). Blood glucose was measured using the glucose oxidase method (Cobas Mira Plus, Roche Diagnostics, GmbH, Montclair, NJ, USA), and insulin was measured by electrochemiluminescence (Modular Analytics, E170, Roche Diagnostics, GmbH, Mannheim, Germany).

Serum total cholesterol, high-density lipoprotein (HDLC) and triglycerides were determined by an enzymatic colorimetric method (Cobas Mira Plus, Roche Diagnostics $\mathrm{GmbH}$, Montclair, NJ, USA). The atherogenic index was calculated as the total cholesterol to HDL-C ratio [29].

\section{Determination of metabolic syndrome, insulin resistance and cardiometabolic risk factors}

The MetS was considered prevalent in subjects who exhibited three or more factors related to waist circumference $\left(W_{\mathrm{MD}} \geq 90 \mathrm{~cm}\right.$ ), hyperglycaemia (glucose $\geq 100 \mathrm{mg} / \mathrm{dL}$ ), dyslipidaemia ( $\mathrm{HDL}-\mathrm{C}<40 \mathrm{mg} / \mathrm{dL}$ ), hypertriglyceridemia $(\geq 150 \mathrm{mg} / \mathrm{dL})$ and/or high blood pressure $(\mathrm{SBP} \geq$ $130 \mathrm{mmHg}$ or $\mathrm{DBP} \geq 85 \mathrm{mmHg}$ ), according to the criteria and cutoff points suggested by Alberti et al. [3].
The homeostasis model assessment (HOMA-IR) was used to estimate IR by using the equation proposed by Matthews et al. [30]. The cutoff value used for the IR diagnosis was 2.7 as suggested by Geloneze et al. [31].

The following values were set as cardiometabolic risk factors [32,33]: triglycerides $\geq 150 \mathrm{mg} / \mathrm{dl}$ (hypertriglyceridemia); total cholesterol $\geq 200 \mathrm{mg} / \mathrm{dl}$ and $\mathrm{HDL}-\mathrm{C}<$ $40 \mathrm{mg} / \mathrm{dl}$ (dyslipidaemia) and glucose $\geq 99 \mathrm{mg} / \mathrm{dl}$ (hyperglycaemia). The participants were classified as hypertensive when systolic and diastolic blood pressures were $\geq$ 140 and $\geq 90 \mathrm{mmHg}$, respectively, [28] and it was considered a cardiometabolic risk when atherogenic index was $\geq 5$ [29].

\section{Lifestyle}

The subjects who participated in this study occupied working positions classified as levels A, B, C, D, and E, or professor. To evaluate how lifestyle and occupation influenced the level of physical activity they were grouped according to their education level and working positions: Group $\mathrm{ABC}$ was composed of technical and administrative staff members, classified as A, B and C, with an education level up to high school. Group DEProf was composed of technical and administrative staff members levels D and E and professors, all college-educated.

The participants were asked about their current smoking status (yes/no) and alcohol consumption (types of alcoholic beverages consumed - beer, wine and/or spirits, frequency and weekly quantity in $\mathrm{mL}$ ). High alcohol consumption was defined as a weekly intake over 21 units [34].

The full version of the International Physical Activity Questionnaire [35] was applied and subjects were categorized as sedentary/moderately active or active/very active.

\section{Statistical Analysis}

Data normality was assessed by the "Smirnov-Kolmogorov" test. For data exposure, we used descriptive statistics composed by mean values and standard deviation or median and interquartile range for continuous variables and frequency for categorical variables. After logarithmic transformation the $\mathrm{WC}_{\mathrm{NR}}, \mathrm{WC}_{\mathrm{MD}}$ and $\mathrm{WC}_{\mathrm{UL}}$ values were compared by ANOVA one way followed by the post hoc Tukey test. The physical activity levels were compared using Chi-Square. The Student's t test was used for independent samples, or its nonparametric equivalent, the Mann-Whitney test, to confirm the existence of differences between mean values per group.

The receiver operating characteristic curve (ROC) was used to detect the best circumference cutoff, sensitivity (Sens) and specificity (Spec) in relation to the cutoff points: $21 \% \mathrm{BF}$ and $25 \% \mathrm{BF}$ and $34.6 \% \mathrm{AAF}$. The areas under the curve and confidence intervals of $95 \%$ (95\% CI) were also determined. The univariate and multivariate regression analysis according to Poisson was used to 
estimate the prevalence ratio (95\% CI) of subjects with hyperglycaemia, dyslipidaemia, hypertensive and MetS (dependent variables). In these analyses the WC cutoff point $(88.8 \mathrm{~cm})$ served as independent variable and the lifestyle factors as covariates.

Data processing and analysis were carried out with the software SPSS version 16.0 (SPSS Inc. Chicago, IL, USA) and STATA 9.1. The value used for all variables and two-tailed analyses was $\mathrm{p} \# 0.05$.

\section{Results}

The general characteristics of the participants are shown in Table 1. There was a high incidence of technical administrative staff members, moderate prevalence of high alcohol consumption (20.3\%) and low prevalence of smoking (12.7\%). In addition, most participants were self-declared as physically active or very active (69.4\%). The BMI assessment showed overweight and obesity in $42.6 \%$ and $12.3 \%$ of subjects, respectively. The following prevalence percentages were observed: $61.7 \%$ for dyslipidaemia, $30.7 \%$ for hypertriglyceridemia, $37.7 \%$ for high atherogenic index, $34.3 \%$ for hypertension, $18.3 \%$ for hyperglycaemia and $9 \%$ for IR. There was a prevalence of $28.3 \%$ for MetS, according to the criteria suggested by Alberti et al. [3]. After comparing the measured waist circumferences $\left(\mathrm{WC}_{\mathrm{NR}}, \mathrm{WC}_{\mathrm{MD}}, \mathrm{WC}_{\mathrm{UL}}\right)$, we observed no statistical difference between $\mathrm{WC}_{\mathrm{NR}}$ and $\mathrm{WC}_{\mathrm{MD}}$. However, $\mathrm{WC}_{\mathrm{UL}}$ was higher than $\mathrm{WC}_{\mathrm{NR}}$ and $\mathrm{WC}_{\mathrm{MD}}$.

The waist circumference values measured at the three different anatomical points showed strong and significant associations $(\mathrm{p} \leq 0.01)$ with overweight, obesity and central obesity (Table 2) as determined by DXA. Interestingly, the $\mathrm{WC}_{\mathrm{UL}}$ was observed as the best measure to identify the prevalence of overweight and obesity, according to the percentages of total body fat $(\geq 20 \%$ and $\geq$ $25 \%$, respectively) and of central obesity (abdominal area fat $\geq 34.6 \%$ ). The $\mathrm{WC}_{\mathrm{UL}}$ best cutoff values for overweight, obesity and central obesity detection as regard to the smallest difference between sensitivity and specificity were $88.8 \mathrm{~cm}, 93.4 \mathrm{~cm}$ and $95.6 \mathrm{~cm}$, respectively.

We used the two smaller $\mathrm{WC}_{\mathrm{UL}}$ cutoff points $(88.8 \mathrm{~cm}$ and $93.4 \mathrm{~cm}$ ) to test its relationships with Mets, IR and cardiometabolic risk factors (Table 3). The occurrence of $\mathrm{WC}_{\mathrm{UL}} \geq 88.8 \mathrm{~cm}$ or 93.4 was positively associated $(\mathrm{p}<0.01)$ with the prevalence of MetS and the cardiometabolic risk factors studied.

We then tested the associations of the prevalence of MetS, IR and cardiometabolic risk factors with the suggested cutoff points for $\mathrm{WC}_{\mathrm{UL}}$ (Table 4). Significant associations of this circumference values for overweight (i.e. $>88.8 \mathrm{~cm}$ ) with the diagnosis of hypertension, dyslipidaemia, hypertriglyceridemia and lower HDL-C, independently of confounding variables (i.e. smoking and frequency of alcoholic beverage consumption) were
Table 1 General characteristics of the studied subjects

\begin{tabular}{|c|c|}
\hline Age (y) & $51(47-54)^{\mathrm{a}}$ \\
\hline$A B C$ work position (number/\%) ${ }^{b}$ & 199/66.3 \\
\hline High alcohol consumption (number/\%) & $61 / 20.3$ \\
\hline Smokers (number/\%) & $38 / 12.7$ \\
\hline \multicolumn{2}{|l|}{ Physical activity levels (number/\%) } \\
\hline Sedentary or moderately active & $92 / 30.6$ \\
\hline Active or very active & $208 / 69.4^{\#}$ \\
\hline Body mass index $\left(\mathrm{kg} / \mathrm{m}^{2}\right)$ & $25.8 \pm 3.43$ \\
\hline Total body fat (\%) & $22.76 \pm 7.14$ \\
\hline Abdominal area fat (\%) & $26.34 \pm 10.52$ \\
\hline$W C_{N R}(\mathrm{~cm})$ & $88.7 \pm 8.4$ \\
\hline$W C_{M D}(\mathrm{~cm})$ & $90.4 \pm 9.5$ \\
\hline$W C_{U L}(\mathrm{~cm})$ & $92.2 \pm 9.3^{*}$ \\
\hline Systolic blood pressure (mmHg) & $126 \pm 14$ \\
\hline Diastolic blood pressure (mmHg) & $81 \pm 10$ \\
\hline Glucose (mg/dl) & $89(83-95)$ \\
\hline Insulin $(\mu \mid \mathrm{U} / \mathrm{mL})$ & $5.2(3.4-8.1)$ \\
\hline HOMA-IR & $1.14(0.73-1.81)$ \\
\hline Total cholesterol (mg/dl) & $214.8 \pm 40.9$ \\
\hline $\mathrm{HDL}-\mathrm{C}(\mathrm{mg} / \mathrm{dl})$ & $44(38-53)$ \\
\hline Triglycerides (mg/dl) & $116.5(82.5-166)$ \\
\hline Atherogenic index & $4.68(3.82-5.60)$ \\
\hline \multicolumn{2}{|c|}{$\begin{array}{l}n=300 ; W C_{N R} \text {, waist circumference at the narrowest waist, } W C_{M D} \text {, waist } \\
\text { circumference at the midpoint between the superior border of the iliac crest and } \\
\text { the inferior margin of the rib, } W C_{U L} \text {, waist circumference at the umbilical line. } \\
\text { HOMA-IR, insulin resistance index; } H D L-C \text {, high density lipoprotein-cholesterol. } \\
\text { aData are mean } \pm S D \text { or median and interquartile range of } 300 \text { subjects, } \\
\text { according to normal distribution of the variables. } \\
{ }^{b} A B C: \text { technical staff at } A, B \text { and } C \text { work positions. } \\
{ }^{*} \text { Statistically different from } W C_{N R} \text { and } W C_{M D} \text {. } \\
{ }^{\#} \text { Statistically different from Sedentary or moderately active. }\end{array}$} \\
\hline
\end{tabular}

observed. All subjects diagnosed with insulin resistance presented $\mathrm{WC}_{\mathrm{UL}}$ higher than $88.8 \mathrm{~cm}$, which made the statistical calculation impossible. Moreover, using $\mathrm{WC}_{\mathrm{UL}}$ higher than $88.8 \mathrm{~cm}$ we observed the increase of $19.3 \%$ in central obesity prevalence as compared to $\mathrm{WC}_{\mathrm{MD}} \geq$ $90 \mathrm{~cm}$ (data not shown). Finally, when we tested the $\mathrm{WC}_{\mathrm{UL}}$ cutoff point for obesity (i.e. $>93.4 \mathrm{~cm}$ ) significant associations with MetS, IR and cardiometabolic risk factors were found.

\section{Discussion}

This study was carried out to determine the anatomical point of waist circumference measurements that best identify overweight, obesity and central obesity, as measured by DXA, in Brazilian middle-aged men residents in the urban area of Viçosa city in the southeastern region of the country and to test the relationships of its cutoff points with metabolic syndrome, insulin resistance and other cardiometabolic risk factors. 
Table 2 AUC (95\% Cl) for overweight, obesity and central obesity and different anatomical points of central circumference in middle-aged men

\begin{tabular}{|c|c|c|c|}
\hline & Overweight (>20\% BF) & Obesity (>25\% BF) & Central obesity (34.6\% AAF) \\
\hline \multicolumn{4}{|l|}{$W C_{N R}$} \\
\hline AUC & $0.877(0.839-0.915)$ & $0.905(0.870-0.940)$ & $0.898(0.861-0.936)$ \\
\hline Cutoff (cm) & 86.4 & 89.4 & 91.6 \\
\hline Sensitivity (\%) & 77.6 & 84.6 & 80.3 \\
\hline Specificity (\%) & 77.9 & 83.6 & 80.4 \\
\hline \multicolumn{4}{|l|}{$W C_{M D}$} \\
\hline AUC & $0.909(0.877-0.942)$ & $0.919(0.890-0.948)$ & $0.897(0.861-0.933)$ \\
\hline Cutoff $(\mathrm{cm})$ & 87.3 & 91.4 & 93.8 \\
\hline Sensitivity (\%) & 82.1 & 83.8 & 80.3 \\
\hline Specificity (\%) & 82.7 & 82.0 & 79.9 \\
\hline \multicolumn{4}{|l|}{$W C_{U L}$} \\
\hline$A \cup C$ & $0.925(0.893-0.953)$ & $0.923(0.894-0.952)$ & $0.902(0.861-0.942)$ \\
\hline Cutoff $(\mathrm{cm})$ & 88.8 & 93.4 & 95.6 \\
\hline Sensitivity (\%) & 82.5 & 84.6 & 81.6 \\
\hline Specificity (\%) & 83.0 & 84.7 & 81.2 \\
\hline
\end{tabular}

AUC, area under curve. $\mathrm{Cl}$, confidence intervals. $\mathrm{WC}_{\mathrm{UL}}$, waist circumference at the umbilical line. $\mathrm{WC}_{\mathrm{MD}}$, waist circumference at the midpoint between the superior border of the iliac crest and the inferior margin of the rib. $W C_{N R}$, waist circumference at the narrowest waist.

We found that $\mathrm{WC}_{\mathrm{UL}}$ exhibited a larger AUC than $\mathrm{WC}_{\mathrm{MD}}$ and $\mathrm{WC}_{\mathrm{NR}}$ and, therefore, it was more accurate in the identification of overweight and obesity making our results in line with the cutoff points recommended by SEEDO [26] and suggested by Bray et al. [27]. We also found that this circumference measure was strongly associated with \%AAF (75th percentile), which makes of it also an accurate measure to identify central obesity. These results confirm the association of WC measurements with total and central adiposity as observed previously in different populations of similar ages. For example, similar findings were demonstrated in male urban residents in a city in the northeast of Brazil $[19,20]$ and also in men from other Latin American countries [18]. Likewise, these associations were found in Canadian (20-79 years old) [15] and Japanese (40-65 years old) [36] men. It is noteworthy that our data indicate the $\mathrm{WC}_{\mathrm{UL}}$ as the best anatomical point to identify overweight, obesity and central obesity. This anthropometric indicator is of practical and clinical relevance in the professional field for both subject assessment and population-based studies. $\mathrm{WC}_{\mathrm{UL}}$ has greater feasibility of location and measurement as well

Table 3 Cardiometabolic risk factors in relation with cutoff of points for waist circumference measured at the umbilical line

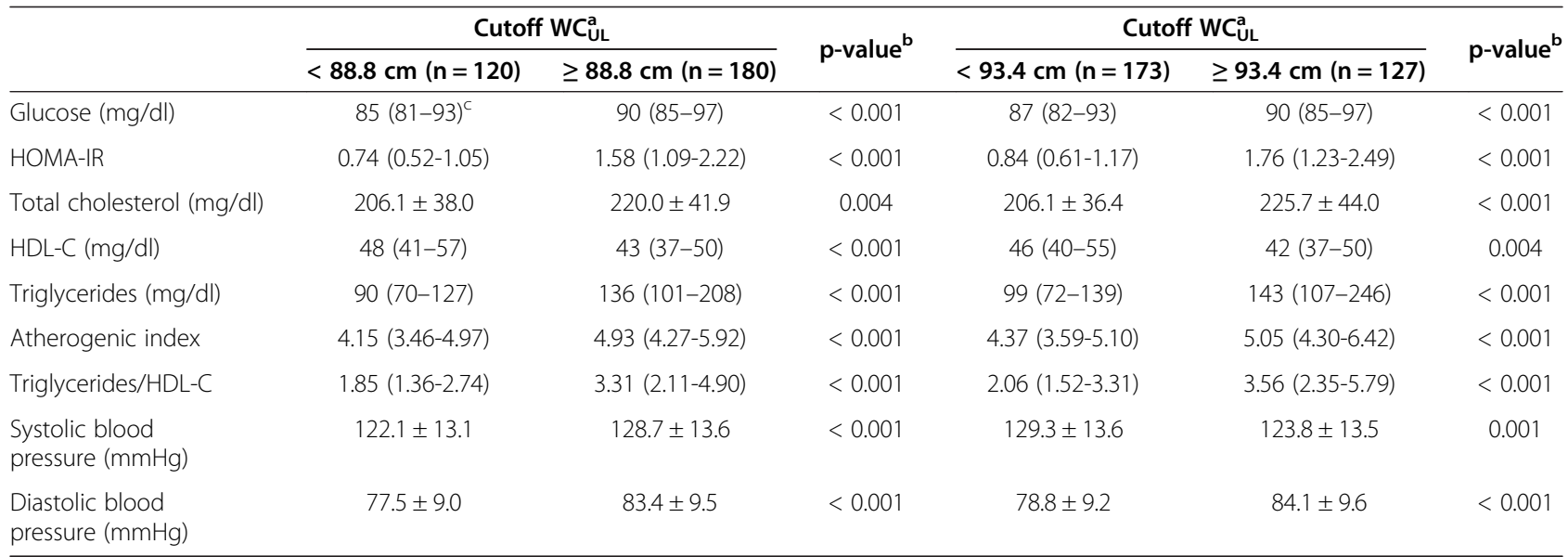

WC $\mathrm{UL}_{\mathrm{UL}}$ : Waist circumference at the umbilical line; HDL-C: high density lipoprotein cholesterol; HOMA-IR: homeostatic model assessment insulin resistance; n: number of subjects.

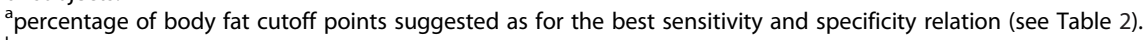

${ }^{b}$-values from Student t-test or Mann-Whitney test.

${ }^{c}$ Data are mean $\pm S D$ or median and interquartile range. 
Table 4 Prevalence ratio of MetS, and cardiometabolic risk factors in relation with cutoff points for WC $\mathrm{WL}_{\mathrm{UL}}$ calculated using a univariate and multivariate regression analysis according to Poisson

\begin{tabular}{|c|c|c|}
\hline & $\geq 88.8 \mathrm{~cm} \mathrm{WC_{ \textrm {UL } } ^ { a }}$ & $\geq 93.4 \mathrm{~cm} \mathrm{WC} C_{\mathrm{UL}}^{\mathrm{a}}$ \\
\hline \multicolumn{3}{|l|}{ Non adjusted ${ }^{\mathrm{b}}$} \\
\hline High fast glucose ${ }^{d}$ & $1.778(1.028-3.073)^{*}$ & $1.519(0.942-2.450)$ \\
\hline Insulin resistance ${ }^{e}$ & $* * *$ & $7.833(2.773-22.128)^{* *}$ \\
\hline High total cholesterol $^{f}$ & $1.174(0.967-1.422)$ & $1.291(1.083-1.538)^{* *}$ \\
\hline Low HDL-C ${ }^{g}$ & $1.316(1.126-1.538)^{* *}$ & $1.295(1.085-1.545)^{* *}$ \\
\hline High triglycerides ${ }^{h}$ & $2.561(1.634-4.015)^{* *}$ & $2.554(1.776-3.673)^{* *}$ \\
\hline Atherogenic index & $2.123(1.472-3.062)^{* *}$ & $1.844(1.374-2.477)^{* *}$ \\
\hline High systolic blood pressure & $1.548(1.088-2.203)^{*}$ & $1.501(1.099-2.051)^{*}$ \\
\hline High diastolic blood pressure ${ }^{k}$ & $2.000(1.354-2.954)^{* *}$ & $1.881(1.359-2.603)^{* *}$ \\
\hline Metabolic Syndrome' & $3.917(1.917-8.001)^{* *}$ & $4.401(2.466-7.855)^{* *}$ \\
\hline \multicolumn{3}{|l|}{ After Adjustment $^{c}$} \\
\hline High fast glucose ${ }^{d}$ & $1.936(1.129-3.318)^{*}$ & $1.632(1.018-2.615)^{*}$ \\
\hline Insulin resistance ${ }^{e}$ & *** & $6.829(2.414-19.317)^{* *}$ \\
\hline High total cholesterol $^{f}$ & $1.154(0.952-1.400)$ & $1.271(1.066-1.515)^{* *}$ \\
\hline Low HDL-C $C^{g}$ & $1.361(1.165-1.591)^{* *}$ & $1.327(1.113-1.582)^{* *}$ \\
\hline High tryglicerides $^{h}$ & $2.516(1.604-3.946)^{* *}$ & $2.500(1.730-3.611)^{* *}$ \\
\hline Atherogenic index & $1.896(1.418-2.534)^{* *}$ & $2.217(1.543-3.186)^{* *}$ \\
\hline High systolic blood pressure & $1.565(1.100-2.227)^{*}$ & $1.549(1.139-2.107)^{* *}$ \\
\hline High diastolic blood pressure ${ }^{k}$ & $1.987(1.346-2.934)^{* *}$ & $1.894(1.366-2.625)^{* *}$ \\
\hline Metabolic Syndrome' & $4.308(2.130-8.727)^{* *}$ & $4.789(2.713-8.452)^{* *}$ \\
\hline
\end{tabular}

Data are expressed as prevalence ratio (95\% confidence interval); MetS: metabolic syndrome; WC $\mathrm{CL}_{\mathrm{U}}$ waist circumference at the umbilical line; $\mathrm{HDL}-\mathrm{C}$ : high density lipoprotein cholesterol.

atwo smaller cutoff points suggested as of the best sensitivity and specificity relation (see Table 2).

bon-adjusted.

cadjusted for age, work position, physical activity level, smoker and alcohol consumption.

dglucose $>99 \mathrm{mg} / \mathrm{dl}$.

e homeostatic model assessment insulin resistance (HOMA-IR) $>2.7$.

f Total cholesterol $>200 \mathrm{mg} / \mathrm{dl}$.

${ }^{\mathrm{g}} \mathrm{HDL}-\mathrm{C}<40 \mathrm{mg} / \mathrm{dl}$.

${ }^{\mathrm{h}}$ Triglycerides $>150 \mathrm{mg} / \mathrm{d}$.

'Total cholesterol/HDL-C $>5$.

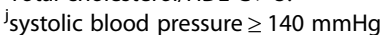

kdiastolic blood pressure $\geq 90 \mathrm{mmHg}$

'Metabolic Syndrome prevalence by Alberti et al., [3]

${ }^{*} \mathrm{p} \leq 0.05 ;{ }^{* *} \mathrm{p} \leq 0.01 ;{ }^{* * *}$ no data (null prevalence in one group).

as lower error occurrence when it is measured, as compared to $\mathrm{WC}_{\mathrm{NR}}$ and $\mathrm{WC}_{\mathrm{MD}}$, especially in obese subjects.

Our results showed significant associations of the cutoff points for $\mathrm{WC}_{\mathrm{UL}}(88.8 \mathrm{~cm}$ and $93.4 \mathrm{~cm})$ with MetS, IR and other cardiometabolic risk factors assessed in this population. For instance, higher values for serum lipid profile, blood pressure and blood glucose, and a higher prevalence of MetS in subjects with $\mathrm{WC}_{\mathrm{UL}}$ greater than $88.8 \mathrm{~cm}$ were observed. In addition, the prevalence of MetS, IR and cardiometabolic risk factors examined were even higher in subjects with $\mathrm{WC}_{\mathrm{UL}}$ above $93.4 \mathrm{~cm}$. Previous studies in different Brazilian geographical regions have pointed to a strong relationship between obesity, especially the central fat accumulation, and the occurrence of NCDs [37]. Thus, our data reinforce those previously reported for the Brazilian population and support the idea that the cutoff points obtained $(88.8 \mathrm{~cm}$ and $93.4 \mathrm{~cm}$ ) are of clinical and economic importance for risk assessment and prevention of obesity related diseases in this population, especially because Brazilian middle-aged men have high prevalence for mortality and morbidity related to NCDs [38].

Our findings represent a scenario in an apparently healthy middle-aged male population. The selected subjects who self-declared suffering from different diseases or disorders or taking medicines that could alter food intake and/or metabolism of nutrients were excluded from our study. In fact, the participants exhibited moderate alcohol consumption, low prevalence of smoking and were physically active. Despite that, the prevalence for overweight, dyslipidaemia, hypertriglyceridemia, high atherogenic index and hypertension was over $30 \%$. Although these data reflect the reality of 
urban populations and alert for the danger of silent cardiometabolic diseases at this age, it cannot be extended to the national Brazilian population since there are regional ethnic groups and differences in eating habits across the country. In addition, it is worth to note that the suggested cutoff value for $\mathrm{WC}_{\mathrm{UL}}$ cannot be generalized to all central circumferences measures as this may lead to possible errors of interpretation and misdiagnosis. In fact, in the present study population $\mathrm{WC}_{\mathrm{UL}}$ was higher than both $\mathrm{WC}_{\mathrm{NR}}$ and $\mathrm{WC}_{\mathrm{MD}}$, which were not statistically different when compared to each other. Moreover, the increase of $19.3 \%$ in the central obesity prevalence using $\mathrm{WC}_{\mathrm{UL}} \geq 88.8 \mathrm{~cm}$ enables more accurate for cardiometabolic risk factors diagnosis.

Finally, our study presents some limitations: (a) despite the fact that the sample size was justified in relation to the target population, studies on larger populations including both gender residents in different regions of Brazil are needed to set cutoff points to the early diagnoses of NCDs nationwide; and (b) although the associations of the $\mathrm{WC}_{\mathrm{UL}}$ cutoff point with MetS, IR and cardiometabolic risk factors remained after being adjusted for age, working position, physical activity level, smoking and alcohol consumption, other factors such as eating habits, marital status and family income were not included.

Overall, this cross-sectional study support the conclusions that: (a) the $\mathrm{WC}_{\mathrm{UL}}$ measure seems to be the best anatomical point to perform waist circumference measurement to identify overweight, obesity and central obesity in urban Southeast Brazilian middle-aged men; and (b) the $\mathrm{WC}_{\mathrm{UL}}$ cutoff point $(88.8 \mathrm{~cm})$ is significantly associated with MetS, IR and cardiometabolic risk factors in the studied population.

\section{Abbreviation \\ NCDs: Non-communicable diseases; MetS: Metabolic syndrome; IR: Insulin resistance; BMI: Body mass index; WC: Waist circumference; $W_{N R}$ : Narrowest waist circumference; $W_{M}$ : Waist circumference measure in midpoint between the superior border of the iliac crest and inferior margin of the rib; WC $C_{U L}$ : Waist circumference measure on umbilical line; DXA: Dual beam X-ray absorptiometry; \%BF: Total body fat; \%AAF: Abdominal area fat; SBP: Systolic blood pressure; DBP: Diastolic blood pressure; HDL-C: High-density lipoprotein; HOMA-IR: Homeostasis model assessment insulin resistance; AUC: Area under curve; ROC: Receiver operating characteristic curve; Sens: Sensitivity; Spec: Specificity.}

\section{Competing interest}

The authors declare that they have no competing interest.

\section{Authors' contributions}

AO: Study design, field work, data collection, analysis, and writing of the manuscript. PGC: Study design, field work, data collection, analysis, and editing of the manuscript. HHMH: Study design, analysis, and writing of the manuscript. JB: Study design, analysis, and editing of the manuscript. MFS and JAR: field work and data collection. AJN: project leader, financial management, and editing of the manuscript. All authors read and approved the final manuscript.

\section{Acknowledgements}

The authors wish to thank all volunteers who participated in this study; the Department of Nutrition and Health and the Department of Physical Education of Federal University of Viçosa for all support in storage and biochemical analysis.

\section{Funding}

This work was supported by the Foundation for Research Support of the State of Minas Gerais (FAPEMIG) and the National Council for Scientific and Technological Development (CNPq/MCT/Brazil). AJN and JB are CNPq fellows.

\section{Author details}

${ }^{1}$ Department of Nutrition and Health, Universidade Federal de Viçosa, Av. PH Rolfs, s/n, Viçosa, Minas Gerais 36570-000, Brazil. ${ }^{2}$ Department of Physical Education Science and Health, Universidade Federal de São João del-Rei, São João del-Rei, Minas Gerais, Brazil. ${ }^{3}$ Department of Physical Education,

Universidade Federal de Viçosa, Viçosa, Minas Gerais, Brazil.

Received: 3 June 2014 Accepted: 22 August 2014

Published: 1 September 2014

\section{References}

1. Preventing Chronic Disease: a Vital Investment. In [http://www.who.int/ chp/chronic_disease_report/contents/foreword.pdf]

2. Panagiotakos DB, Pitsavos C, Skoumas $Y$, Lentzas $Y$, Papadimitriou L, Chrysohoou C, Stefanadis C: Abdominal obesity, blood glucose and apolipoprotein $B$ levels are the best predictors of the incidence of hypercholesterolemia (2001-2006) among healthy adults: the ATTICA study. Lipids Health Dis 2008, 7:11.

3. Alberti KG, Eckel RH, Grundy SM, Zimmet PZ, Cleeman Jl, Donato KA, Fruchart JC, James WP, Loria CM, Smith SC Jr: Harmonizing the metabolic syndrome: a joint interim statement of the International Diabetes Federation Task Force on Epidemiology and Prevention; National Heart, Lung, and Blood Institute; American Heart Association; World Heart Federation; International Atherosclerosis Society; and International Association for the Study of Obesity. Circulation 2009, 120(16):1640-1645.

4. Brasil: Vigitel Brazil 2013: protective and risk factors for chronic diseases by telephone survey. Brasilia/DF: Health Minister; 2014.

5. Oliveira EP, Souza MLA, Lima MDA: Prevalência de síndrome metabólica em uma área rural do semi-árido baiano. Ara Bras Endocrinol Metabol 2006, 50:456-465.

6. Rezende FA, Rosado LE, Ribeiro Rde C, Vidigal Fde C, Vasques AC, Bonard IS, de Carvalho CR: Body mass index and waist circumference: association with cardiovascular risk factors. Arq Bras Cardiol 2006, 87(6):728-734.

7. Mlinar B, Marc J, Janez A, Pfeifer M: Molecular mechanisms of insulin resistance and associated diseases. Clin Chim Acta 2007, 375(1-2):20-35.

8. Kurtoglu S, Akin L, Kendirci M, Hatipoglu N, Elmali F, Mazicioglu M: The absence of insulin resistance in metabolic syndrome definition leads to underdiagnosing of metabolic risk in obese patients. Eur J Pediatr 2012, 171(9):1331-1337.

9. Coutinho T, Goel K, Correa de Sa D, Kragelund C, Kanaya AM, Zeller M, Park JS, Kober L, Torp-Pedersen C, Cottin Y, Lorgis L, Lee SH, Kim YJ, Thomas R, Roger VL, Somers VK, Lopez-Jimenez F: Central obesity and survival in subjects with coronary artery disease: a systematic review of the literature and collaborative analysis with individual subject data. J Am Coll Cardio/ 2011, 57(19):1877-1886.

10. Snowdon W, Malakellis M, Millar L, Swinburn B: Ability of body mass index and waist circumference to identify risk factors for non-communicable disease in the Pacific Islands. Obes Res Clin Pract 2014, 8(1):e36-e45.

11. Racette SB, Evans EM, Weiss EP, Hagberg JM, Holloszy JO: Abdominal adiposity is a stronger predictor of insulin resistance than fitness among 50-95 year olds. Diabetes Care 2006, 29(3):673-678.

12. Korhonen PE, Jaatinen PT, Aarnio PT, Kantola IM, Saaresranta T: Waist circumference home measurement-a device to find out patients in cardiovascular risk. Eur J Public Health 2009, 19(1):95-99.

13. Mason C, Katzmarzyk PT: Effect of the site of measurement of waist circumference on the prevalence of the metabolic syndrome. Am J Cardio/ 2009, 103(12):1716-1720.

14. Wang J, Thornton JC, Bari S, Williamson B, Gallagher D, Heymsfield SB, Horlick M, Kotler D, Laferrere B, Mayer L, Pi-Sunyer FX, Pierson RN Jr: Comparisons of waist circumferences measured at 4 sites. Am J Clin Nutr 2003, 77(2):379-384.

15. Nakazone MA, Pinheiro A, Braile MC, Pinhel MA, de Sousa GF, Pinheiro S Jr. Brandao AC, Toledo JC, Braile DM, Souza DR: [Prevalence of metabolic syndrome using NCEP-ATPIII and IDF definitions in Brazilian individuals]. Rev Assoc Med Bras 2007, 53(5):407-413. 
16. Patry-Parisien J, Shields M, Bryan S: Comparison of waist circumference using the World Health Organization and National Institutes of Health protocols. Health Rep 2012, 23(3):53-60

17. Ness-Abramof R, Apovian CM: Waist circumference measurement in clinical practice. Nutr Clin Pract 2008, 23(4):397-404.

18. Aschner P, Buendia R, Brajkovich I, Gonzalez A, Figueredo R, Juarez XE, Uriza F, Gomez AM, Ponte Cl: Determination of the cutoff point for waist circumference that establishes the presence of abdominal obesity in Latin American men and women. Diabetes Res Clin Pract 2011, 93(2):243-247.

19. Roriz AK, de Oliveira CC, Moreira PA, Eickemberg M, Medeiros JM, Sampaio LR: Methods of predicting visceral fat in Brazilian adults and older adults: a comparison between anthropometry and computerized tomography. Arch Latinoam Nutr 2011, 61(1):5-12.

20. Barbosa PJB, Lessa I, Almeida Filho N, Magalhães LBNC, Araújo J: Criteria for central obesity in a Brazilian population: impact on the metabolic syndrome. Arq Bras Cardiol 2006, 87:407-414.

21. Dean AG, Dean JA, Colombier D, Brendel KA, Smith DC, Burton AH, Dicker RC, Sullivan K, Fagan RF, Arner TG: Epi Info, version 6: a word processing, database, and statistics program for public health on IBM-compatible microcomputers. Atlanta, Georgia, USA: Center for Disease Control and Prevention; 1996.

22. Gordon CCCWC, Roche AF: Stature, recumbent length and weight. In Anthropometric Standardization Reference Manual. Edited by Lohman TGR AE, Martorell R. Illinois: Human Kinetics Book; 1988:3-8.

23. BMI Classification. In [http://apps.who.int/bmi/index.jsp?introPage=intro_3. html]

24. Lohman TG: Advances in body composition assessment. Champaign, IL: Human Kinetics; 1992.

25. Alonso AL, Munguia-Miranda C, Ramos-Ponce D, Hernandez-Saavedra D, Kumate J, Cruz M: Waist perimeter cutoff points and prediction of metabolic syndrome risk. A study in a Mexican population. Arch Med Res 2008, 39(3):346-351.

26. Salas-Salvado J, Rubio MA, Barbany M, Moreno B: SEEDO 2007 Consensus for the evaluation of overweight and obesity and the establishment of therapeutic intervention criteria. Med Clin (Barc) 2007, 128(5):184-196. quiz 181 p following 200

27. Bray G, Bouchard C, James WPT: Definitions and proposed current classifications of obesity. In Handbook of obesity. Edited by Bray G, Bouchard C, James WPT. Nueva York: Marcek Dekker; 1998:31-40.

28. IVI Brazilian Guidelines on Hypertension]: [VI Brazilian Guidelines on Hypertension]. Arq Bras Cardiol 2010, 95(1 Suppl):1-51.

29. Castelli WP, Garrison RJ, Wilson PW, Abbott RD, Kalousdian S, Kannel WB: Incidence of coronary heart disease and lipoprotein cholesterol levels. The Framingham Study. JAMA 1986, 256(20):2835-2838.

30. Matthews DR, Hosker JP, Rudenski AS, Naylor BA, Treacher DF, Turner RC: Homeostasis model assessment: insulin resistance and beta-cell function from fasting plasma glucose and insulin concentrations in man. Diabetologia 1985, 28(7):412-419.

31. Geloneze B, Vasques AC, Stabe CF, Pareja JC, Rosado LE, Queiroz EC, Tambascia MA: HOMA1-IR and HOMA2-IR indexes in identifying insulin resistance and metabolic syndrome: Brazilian Metabolic Syndrome Study (BRAMS). Arq Bras Endocrinol Metabol 2009, 53(2):281-287.

32. Sposito AC, Caramelli B, Fonseca FA, Bertolami MC, Afiune Neto A, Souza $A D$, Lottenberg AM, Chacra AP, Faludi AA, Loures-Vale AA, Carvalho AC, Duncan B, Geloneze B, Polanczyk C, Rodrigues Sobrinho CR, Scherr C, Karla C, Armaganijan D, Moriguchi E, Saraiva F, Pichetti G, Xavier HT, Chaves H, Borges JL, Diament J, Guimarães Jl, Nicolau JC, dos Santos JE, de Lima JJ, Vieira JL, et al: IV Brazilian Guideline for Dyslipidemia and Atherosclerosis prevention: Department of Atherosclerosis of Brazilian Society of Cardiology. Ara Bras Cardiol 2007, 88(Suppl 1):2-19.

33. Souza CF, Gross JL, Gerchman F, Leitao CB: [Prediabetes: diagnosis, evaluation of chronic complications, and treatment]. Ara Bras Endocrinol Metabol 2012, 56(5):275-284.

34. Duncan BB, Schmidt MI, Giugliani ERJ: Medicina ambulatorial: condutas de atenção primária baseada em evidências., 3rd ed. edn. Porto Alegre-RS: Artmed Editora; 2004.

35. Craig CL, Marshall AL, Sjostrom M, Bauman AE, Booth ML, Ainsworth BE, Pratt $M$, Ekelund U, Yngve A, Sallis JF, Oja P: International physical activity questionnaire: 12-country reliability and validity. Med Sci Sports Exerc 2003, 35(8):1381-1395.
36. Oka R, Kobayashi J, Yagi K, Tanii H, Miyamoto S, Asano A, Hagishita T, Mori M, Moriuchi T, Kobayashi M, Katsuda S, Kawashiri MA, Nohara A, Takeda Y, Mabuchi $H$, Yamagishi M: Reassessment of the cutoff values of waist circumference and visceral fat area for identifying Japanese subjects at risk for the metabolic syndrome. Diabetes Res Clin Pract 2008, 79(3):474-481.

37. Veloso HJ, da Silva AA: [Prevalence and factors associated with abdominal obesity and excess weight among adults from Maranhao, Brazil]. Rev Bras Epidemiol 2010, 13(3):400-412.

38. Laurenti R, Jorge MHPM, Gotlieb SLD: Epidemiological profile of men: morbidity and mortality. Cien Saude Colet 2005, 10(1):35-46.

doi:10.1186/1476-511X-13-141

Cite this article as: de Oliveira et al:: Waist circumference measures: cutoff analyses to detect obesity and cardiometabolic risk factors in a Southeast Brazilian middle-aged men population - a cross-sectional study. Lipids in Health and Disease 2014 13:141.

\section{Submit your next manuscript to BioMed Central and take full advantage of:}

- Convenient online submission

- Thorough peer review

- No space constraints or color figure charges

- Immediate publication on acceptance

- Inclusion in PubMed, CAS, Scopus and Google Scholar

- Research which is freely available for redistribution 